\title{
LA BATLLIA GENERAL DE LA PART DEL REGNE DE VALĖNCIA DELLÀ XIXONA
}

\author{
MARIA TERESA FERRER MALLOL \\ Institució «MILA Y FONTANALS", C. S. I. C.
}

La conquesta del regne de Múrcia per Jaume II, en el curs de la guerra contra Castella de 1296-1304 (1), comportà una nova configuració governativa i administrativa d'aquestes terres, seguint el model establert a Catalunya, a Aragó i al regne de València, amb algunes modificacions de detall per tal d'adaptar-lo als privilegis locals. Així, doncs, el govern del regne fou confiat a un procurador i l'administració del Patrimoni reial fou encomanada a un batlle general del regne de Múrcia.

La partició del regne de Múrcia entre Castella i la Corona catalanoaragonesa, pactada a la sentència arbitral de Torrellas de 1304 (2), alterà aquest esquema només en l'àmbit territorial, més reduït, i en el nom de les institucions político-administratives, que ja no podien titular-se del regne de Múrcia, nom que, amb la capital, quedava per a Castella; tot primer, doncs, s'intitularen «de les terres dellà Xixona» i, després de llur anexió formal al regne de València el 1308 (3), «de la part del regne de València dellà Xixona».

\section{FUNCIONS DEL BATLLE GENERAL}

Com a Catalunya o com a Aragó i com a la resta del regne de València (4), també a les terres dellà Xixona el batlle general fou el cap suprem de l'administració del Patrimoni reial, que comprenia domini públic (mines, salines, pastures, boscos, aigües, drets de caça i pesca), monopolis reials de serveis públics (molins, forns, carnisseries, banys, etc.), rendes i drets dominicals o emfitèutics (delmes, tasques, etc., de l'una banda i censos, drets d'establiment emfitèutic, firma, lluïsmes, etc., de l'altra), impostos reials de diversa 
mena sobre les persones dels jueus i sarraïns, considerats com una part del "tresor» reial, impostos sobre pas marítim o terrestre de bestiar o mercaderíes, drets de duana, etc.

De la mateixa manera que el batlle era el receptor de les rendes i dels impostos reials, també era el pagador de les despeses de la Corona en el territori que administrava: salaris dels oficials reials, despeses de conservació o reparació d'edificis públics, castells, etc.

El batlle general només havia de retre comptes al mestre racional del rei o a qui el monarca designés, mentre que ell podia demanar comptes a tots els oficials menors dependents de la batllia general.

A més de la vessant pròpiament econòmica, el càrrec de batlle general tenia també una vessant judicial i governativa, ja que tenia competència en ambdues esferes sobre jueus i sarrïns, derivades de llur consideració, com ja hó hem dit, de tresor del rei. Tenia també jurisdicció sobre afers marítims i concedia, per exemple, llicències de navegació, autoritzava armaments en cors, etc. D'altra banda, també era competent en les qüestions judicials per causa de rendes i drets patrimonials i fiscals.

El batlle general era, a més, el cap jeràrquic dels batlles locals i del personal lligat a la batllia.

El nomenament del batlle general solia fer-se a beneplàcit, és a dir, revocable a voluntat del monarca; només en alguns casos era concedit amb caràcter vitalici, sovint després d'un temps d'exercici de la persona afavorida amb aquesta distinció.

\section{BATLLIA GENERAL DEL REGNE DE MÚRCIA}

Com a antecedent immediat de la batllia de les terres dellà Xixona, ens ocuparem tambié de l'efímera batllia general del regne de Múrcia.

\section{Bernat Colom o Colomet}

El primer titular de la batllia general murciana fou Bernat Colom, en algunes ocasions citat com a Colomet, un ciutadà de València, a qui fou atorgada a beneplàcit amb un salari de 2.000 sous reials (5). Sens dubte la tasca de Bernat Colom fou feixuga: a la feina d'organitzar una nova administració , cosa sempre complexa, encara que pogués servir-se en part del sistema castellà anterior, hi afegia el control dels béns confiscats i llur repartiment entre els 
nous concessionaris. El 31 de maig de 1296, passat el termini donat pel rei Jaume II perquè els habitants del regne de Múrcia el reconeguessin com a rei, el monarca demanà informació a Bernat Colom sobre els béns que els rebels, que no havien efectuat aquest recononeixement, posseïen als termes d'Oriola, de Múrcia i qualssevol altres llocs i sobre la qualitat d'aquests béns: si eren francs o obligaven a prestar serveis a la Corona (6). Això vol dir que Bernat Colom i la gent que devia tenir a les seves ordres hagueren de treballar durament i ràpida per a fer l'inventari que el monarca sol.licitava. Ell mateix i el qui seria el seu succesor en el càrrec, Ferrer Descortell, figuraren entre els beneficiaris de les concessions de béns de rebels; Bernat Colom rebé unes cases que havien estat de Pero «Enriquín» de Arana, a la parròquia de Santa Maria de la ciutat de Múrcia (7), i Ferrer Descortell, que era llavors escrivà reial, rebé cases i vinyes a Múrcia i més tard els béns que havien pertangut a Martín Ximénez de Sádava (8).

\section{Ferrer Descortell}

Pel febrer de 1298, Bernat Colom o Colomet fou substituiit per Ferrer Descortell, el qual acumulà al càrrec de batile general del regne de Múrcia el d'escrivà de ració en el regne, amb l'encàrrec d'efectuar els pagaments a les tropes destinades a la frontera (9). A aquest efecte portava un llibre d'estipendiats, en el qual constaven els noms de les persones designades per a prestar servei a la frontera, amb el tipus de servei que prestaven: amb un cavall armat o alforrat, o més, a peu, etc. Aquest llibre servia de base per a fer els pagaments segons la categoria de cadascú (10). El control sobre l'administració dels castells també era competència seva, però no pas com a escrivà de ració de l'exèrcit fronterer, sinó com a batlle general; és per aquesta raó que hom pot trobar entre les cartes de Jaume II un albarà dels comptes que Rodrigo de Biscarra havia retut al batlle general per la tinença del castell de Cartagena (11).

Per aquest motiu, el primer de maig de 1303, Jaume II li envià la llista de les retinences que havia de pagar a cada castell del regne. Aquesta llista indica el nombre de soldats de la guarnició de cada castell i la despesa que suposaven per causa de la soldada, companatge i vianda que hom els proporcionava. El mateix document conté, a més, els salaris dels homes a cavall, amb distinció de cavalls armats i alforrats, que havien de defensar el regne, i els del seguici del procurador i les instruccions sobre la destinació que Ferrer Descortell havia de donar al «setmo» pertocant al rei en les cavalcades contra l'enemic. El «setmo», segons aquestes instruccions, havia de servir per a pagar les esmenes dels cavalls perduts a la guerra, per a pagar els salaris 
dels soldats i per a repartir entre els qui haguessin participat en les cavalcades, tal com era costum (12).

Una altra llista posterior, del 18 de maig, completa la que acabem de comentar amb la relació dels noms dels nobles i cavallers que servien en el regne de Múrcia i el nombre de cavalls armats o alforrats que tenien en servei. Sens dubte era la pauta que havia de servir a Ferrer Descortell per a pagar les soldades (13).

Però, certament, allò que li degué portar més feina degué ésser fer l'inventari de terres, cases i béns que havien passat al fisc a causa de la revolta - l'absència de llurs antics propietaris i llur nova concessió. El 28 de març de 1298, en efecte, Jaume II li donà poders per a establir per un temps determinat o a perpetuïtat, amb un cens anual, aquelles heretats i béns (14). Sembla que, per motius d'honestedat en el càrrec, al batlle general no li era permès d'acudir com a comprador a la venda o l'establiment emfitèutic d'aquests béns si no era amb una autorització molt especial del rei; aquesta autorització li fou concedida, el 18 d'abril de 1303, perquè pogués comprar els béns que Nicolás Pérez —el qui havia estat alcaid d'Alacant- i la seva muller posseien a l'horta de Múrcia (15).

Sembla que durant alguns mesos Ferrer Descortell monopolitzà tota l'administració del Patrimoni del regne de Múrcia a les seves mans. Des del moment de la conquesta de les ciutats i viles del regne, Jaume II hi havia nomenat batlles locals en totes, com era habitual a les viles reials catalanes, per exemple. Però el 1303, constret, potser, a fer economies a causa de les despeses de la guerra amb Castella, decidi que hom podia prescindir dels batlles locals i que el batlle general podia administrar directament les rendes reials en aquests llocs. Així, doncs, el 30 d'abril de 1303, el rei manà a Ferrer Descortell que revoqués els nomenaments dels batlles locals i administrés ell directament totes les rendes (16). Aquest procediment no degué donar gaires bons resultats, perquè abans d'un any, el primer de febrer de 1304, fou nomenat un nou batlle a Oriola (17) i, el 7 d'octubre del mateix any, un altre a Alacant (18).

\section{LA BATLLIA GENERAL DE LES TERRES DELLÀ XIXONA FINS A MITJAN SEGLE XIV}

\section{Ferrer Descortell.}

La partició del regne de Múrcia entre la Corona catalano-aragonesa i Castella, en virtut de la sentència arbitral de Torrellas, del 8 d'agost de 1304, obli- 
gà Jaume II a fer nous nomenaments dels oficials reials, la jurisdicció dels quals quedava restringida a la part que li havia correspost. Així, doncs, el 3 de desembre de 1304, Ferrer Descortell rebé el seu nou nomenament de batlle general del rei a la seva terra dellà Xixona («officium baiulie terre nostre ultra Sexonam») amb una durada subjecta al beneplàcit reial i salari de 2.000 sous anuals (19).

Hem trobat la definició de comptes atorgada pel mestre racional, Bernat Rodera, a favor de Ferrer Descortell donant per bons els comptes que li havia presentat i que corresponien als darrers tres anys d'existència de la batllia general del regne de Múrcia i al primer de la batllia della Xixona, del primer de gener de 1302 al 31 de desembre de 1305. El 1302 els ingressos havien pujat a la quantitat de 59.666 sous, 6 diners de reials, mentre que les despeses de salaris d'oficials, retinences de castells, obres, etc., havien pujat a 57.974 sous, 10 diners, és a dir, que hi havia hagut un petit superàvit d'ingresos. El 1303 aquestes quantitats havien estat, respectivament, 51.623 sous, 6 diners i 50.260 sous, 6 diners. El 1304 els comptes foren una mica complicats perquè comprengueren tot el regne de Múrcia fins al novembre de $1304 \mathrm{i}$, de llavors fins a final d'any, només la part del regne corresponent a Jaume II; les rendes d'Elx hi foren computades des del 8 d'agost; tanmateix, Elda i Novelda no hi foren compreses perquè el rei havia donat aquestes poblacions i llurs termes a la reina. Tot plegat, els ingressos pujaren a uns 95.113 sous, 10 diners (les centenes, desenes i unitats no es llegeixen bé) i 400 cafissos de civada, mentre que les despeses pujaren a 89.884 sous, 9 diners i 400 cafissos de civada.

El 1305 els ingresos pujaren encara més perquè hi quedaren englobades durant tot l'any les rendes d'Elx, que compensaren amb escreix la pèrdua econòmica que significava la renúncia a les resta del regne de Múrcia. Els ingressos foren de 98.232 sous, xifra que fou superada per les despeses, que pujaren a 101.340 sous. L'extraordinari augment de les despeses fou motivat, segurament, per obres de reparació als castells; almenys hi ha constància que hom permeté a Ferrer Descortell retenir els 5.000 sous de superàvit que havia tingut durant els quatre anys, perquè les obres del castell d'Oriola pujaven ja a 6.837 sous, 6 diners. Però allò que crida més l'atenció és l'augment d'ingressos determinat per la inclusió de les rendes d'Elx. Només quatre mesos d'inclusió d'Elx havien fet passar les rendes del regne de Múrcia de 51.623 sous el 1303 (59.666 el 1302) a 95.113 sous el 1304. La inclusió de les rendes d'Elx de tot l'any, el 1305, malgrat la pèrdua de la meitat del regne de Múrcia, feren pujar els ingressos reials a 98.232 sous, com ja ho hem dit (20). A la vista d'aquestes xifres hom comprèn l'interès de Jaume II 
per a tenir la propietat d'Elx, que era de don Juan Manuel, a més de la jurisdicció.

El 1309, Ferrer Descortell afegí a les competències que ja tenia algunes altres, concretament la recaptació de determinats impostos als llocs pertanyents a la reina Blanca, és dir, a Elda i a Novelda i a Asp; la parella reial havia acordat que aquests impostos serien per al monarca, que els dedicaria exclusivament a pagar els salaris dels membres de la casa reial. Un primer document del 8 de gener de 1309, fet sobre el patró del destinat al batlle general del regne de València, deia que aquestes competències eren els esdeveniments judicials, és a dir, multes i totes altres penes pecuniàries, monedatge i drets de sortida dels sarraïns i de mercaderies per terra i per mar. En el mateix document, el rei exhortava el batlle general a exigir tots els drets reials i a lliurar-ne el producte integrament al tresorer, Pere Marc, que el destinaria a pagar els salaris i quitacions dels qui formaven la seva cort (21). Dos mesos després, el rei havia d'expedir una nova comunicació a Ferrer Descortell per a aclair i concretar les competències que tenia als llocs de la reina i que ell havia interpretat d'una manera massa àmplia. Pertocaria a Ferrer Descortell recaptar, en els llocs de la reina habitats per sarraïns, els esdeveniments judicials provinents de causes criminals, és a dir, si la pena de mort era commutada per una composició pecuniària; en cavi, pertocaria al batlle de la reina la composició que substituís, per exemple, una pena d'assots. D'altra banda, el monedatge, les quèsties i la redempció d'exèrcit ja li pertanyien i els feia exigir per col.lectors especials. En els llocs habitats exclusivament per sarraïns, Ferrer Descortell no podria intervenir-hi ni tan sols per a recaptar aquells esdeveniments, sinó que ho faria el batlle de la reina, el qual li retria comptes d'això i li ho lliuraria (22).

Finalment, un any més tard, pel desembre de 1310, a causa de la mort de la reina Blanca, l'administració de les rendes d'Elda, de Novelda i d'Asp passà a Ferrer Descortell, mentre que Bernat de Granyana, que era qui ho administrava fins llavors, fou advertit que deixés de fer-ho (23).

A part de la batllia, Ferrer Descortell es féu càrrec també dues vegades durant el seu mandat, el 1306-1307 i el 1312, de la col.lecta del monedatge o morabetí, impost que es pagava, com se sap, cada set anys i per al qual el rei designava un col.lector especial (24).

D'altres vegades, en casos d'emergència, hagué d'ocupar-se d'afers que eren competència del portantveus de procurador o del seu lloctinent, segurament perquè aquest era absent de les viles més pròximes a la frontera. Conservem una carta seva, del primer de juny del 1308, escrita a Elx, en la qual 
informava el rei Jaume II de les notícies que li arribaven a través dels espies moros que, d'acord amb l'arrais de Crevillent, havia enviat a Granada i d'altres espies enviats a Lorca pel batlle d'Oriola a requesta seva. Segons aquestes noticies, els granadins es preparaven per a envair les terres dellà Xixona, invasió que Ferrer Descortell considerava imminent. Per aquest motiu havia manat a Llop López de Vaylo i a Ferrer Descloquer que es tanquessin a Villena, ja que tothom es recollia a les fortaleses (25). Dos dies després, el 3 de juny, Ferrer Descortell tornà a informar el rei de les noves que li havien arribat des d'Oriola sobre la invasió granadina (26), ja que el justícia i el jurats d'Oriola procuraven mantenir informats tant el lloctinent, Pero López de Rufes, com Ferrer Descortell mateix (27), talment com si tots dos tinguessin una responsabilitat semblat en aquesta matèria, bé que, en realitat, l'organització de la defensa era competència del lloctinent. Igualment s'adreçaren a l'un i a l'altre el consell $i$ els homes de Guardamar per a demanar ajut quan temien, aquells mateixos dies, ésser l'objectiu de l'atac de l'exèrcit nassarita (28).

Els nostres documents proporcionen moltes més dades sobre l'actuació de Ferrer Descortell en les qüestions més diverses, cosa natural, atès el gran nombre de competències que tenia, però no ens en podem ocupar ara amb detall.

No coneixem, però, els motius pels quals fou destituit el 1314. És possible que fos en aquesta època quan adquiri el senyoriu d'Agost, en el terme d'Alacant, i que el fet d'ésser propietari d'un senyoriu d'importància fos incompatible amb la funció de batlle general. Més endavant, en efecte, mantingué un llarg plet amb Alacant a causa dels límits, dels emprius de pastura i llenya que els alacantins asseguraven tenir al seu terme i del cabeçatge dels sarraïns d'Agost que, segons Alacant, li corresponia de cobrar. Aquest litigi degué provocar penyores contra els habitants d'Agost, perquè el 1319 el rei posà sota el seu guiatge Ferrer Descortell, la seva muller, fills i familia i el lloc d'Agost amb els seus habitants, tant cristians com sarraïns, amb la prohibició de prendre'ls penyores (29).

Ferrer Descortell fou, segurament, un dels batlles generals més distingits dels qui actuaren a la frontera meridional. El 1306 el rei havia premiat els seus serveis enfranquint-lo amb çaràcter vitalici de quèstia, peita, cena, servei, subsidi, bovatge, monedatge, exèrcit, host i cavalcada i llur redempció (30) i, el 1316, dos anys després de la seva destitució com a batlle general de les terres dellà Xixona, li demostrava la seva estima atorgant-li el càrrec de batlle general del regne de València (31), que era força més important que el que havia tingut, tant per l'extensió del territori com pel prestigi de la seva major antigui- 
tat, que de fet li donava una preeminència sobre la batllia dellà Xixona en alguns aspectes, com ho veurem més endavant. Consta que morí abans del $1321 \mathrm{i}$, com que havia quedat a deure alguna quantitat important a la cort, el lloc d'Agost hagué d'ésser venut per a pagar el deute (32).

\section{Guillem Montserrat}

El 1314 Ferrer Descortell fou succeït al front de la batllia general de les terres dellà Xixona per un veí d'Alacant, Guillem Montserrat, un home de fidelitat a tota prova que, pel juny de 1296, havia sortit d'Elx, domini de don Juan Manuel, que no reconeixia la sobirania de Jaume II, per anar a establir-se amb la seva família a Alacant, sota el domini d'aquest monarca (23). Li fou assignat un salari anual de 2.000 sous reials, completat amb 300 més per la batllia de les valls d'Elda i Novelda, que havia estat agregada a la batllia general ja en temps de Ferrer Descortell, a causa de la mort de la reina (34).

\section{Joan Rolf}

Guillem Montserrat no ocupà el càrrec més enllà de set mesos. El mes d'agost de 1314 ja era succeït per un altre veí d'Alacant, Joan Rolf, amb les mateixes condicions econòmiques $i$ de competències que acabem de detallar en referir-nos a Guillem Montserrat (35).

Joan Rolf o Raolf tenia ja per concessió reial, des de 1301, l'escrivania pública d'Alacant amb caràcter vitalici, el dret a ésser succeït per un dels seus fills i la facultat, tant ell com el seu successor, de servir-la per mitjà d'un substitut (36).

Sabem que prengué possessió del nou càrrec el 14 d'agost de 1314 i que l'exercí fins al desembre del 1317, en què morí (37). El 1316 Joan Rolf acumulà al seu càrrec de batlle el de procurador fiscal, la funció del qual era d'ocupar-se dels drets fiscals i castigar els oficials reials que incomplissin llurs obligacions. El portantveus de procurador, Arnau de Torrelles, havia recomanat al rei que creés aquest càrrec, que segons ell era necessari, i li havia indicat com a persona per a exercir-lo Arnau Vermell, d'Oriola. El rei traspassà la decisió sobre aquesta qüestió, tant la creació del càrrec com la designació d'Arnau Vermell, a Joan Rolf, però dos mesos després, li manà que el revoqués $\mathrm{i}$ assumis ell mateix el càrrec, ja que els cavallers i prohoms d'Oriola li havien fet saber que amb el batlle ja n'hi havia prou per a fer la feina de procurador fiscal (38).

Al començament de desembre, alguna malaltia devia fer preveure que Joan Rolf no viuria gaire temps, perquè el 10 d'aquest mes Jaume II concedí 
la batllia dellà Xixona, des del primer de gener següent, a Jaume Andreu, ciutadà de València, amb el salari acostumat (39).

En aquella data, el rei encara no sabia que Joan Rolf hagués mort, perquè li envià una comunicaciòn referent a un afer del seu càrrec (40). No degué trigar gaire a morir-se, però, perquè en el seu llibre de comptes consta, com hem dit, que traspassà aquest mes i que Jaume Desclapers acabà els comptes d'aquell any, bé que a Joan Rolf li fou computat el salari de tot el mes de desembre (41).

Jaume Desclapers s'encarregà també de retre comptes a la cort de l'administració de la batllia de setembre a desembre, ja que Joan Rolf els havia retuts personalmente fins al 31 d'agost d'aquell any.

D'altra banda el seu marmessor, Ponç Bonivern, veí d'Alacant, degué encarregar-se de fer el balanç darrer de tot el que Joan Rolf pogués deure a la cort o viceversa, ja que, malgrat que els batlles generals lliuraven de tant en tant els excedents dels ingressos, deduïdes les despeses, hom no solia fer el balanç definitiu fins després de la mort o de la separació del càrrec. Fa suposar que la cort tenia algun interès especial en la tasca de Ponç Bonivern el fet que, per causa de la marmessoria, aquest darrer fos dispensat durant vuit anys de poder ésser obligat a acceptar els càrrecs d'assesor, de justícia o qualsevol altre ofici públic d'Alacant (42). De qüestions a resoldre no li'n mancaren: el 1321, per exemple, el batlle de Crevillent, Bartomeu Romeu, es queixà que havia estat lloctinent de Joan Rolf a Elx, mentre aquest n'era batlle general, i que no havia tingut cap recompensa ni pel treball ni per les despeses i demanà, per tant, un salari pel temps que havia treballat. Jaume II atengué la petició i manà a Llorenç Fritós, jurista d'Oriola, que li fes assignar un salari i l'hi fes pagar dels béns de Joan Rolf (43). No sabem si valia per a un cas com aquest el guiatge que el rei havia atorgat a la vídua, als fills, filles i béns de Joan Rolf poc després de la seva mort, el 10 de març de 1318, potser per a deslliurar-los d'exigències precipitades dels creditors (44).

\section{Jaume Andreu}

El successor de Joan Rolf, Jaume Andreu, havia estat abans batlle de Xàtiva (45). El seu nomenament com a batlle dellà Xixona sembla que fou una mena de compra del càrrec, ja que el mateix dia del nomenament el rei reconegué deure-li una quantitat de diners no especificada, que el monarca li assignà sobre les rendes de la batllia dellà Xixona; el document remetia per als detalls del deute al registre de tresoreria, on havia estat inscrit. Jaume II es comprometé a conservar-li el càrrec mentre no li retornés la quantitat deguda 
i deu anys després, el rei Alfons, fill i sucessor de Jaume II, ratificà aquest compromís el 25 de novembre de 1327 (46).

Jaume Andreu tingué un salari anual de 2.000 sous reials com els seus predecessors en el càrrec (47), però no tingué tantes competències com els seus antecessors immediats: la batllia de la vall d'Elda, que comprenia Elda, Novelda i Asp, fou administrada primer per Joan Pérez d'Avesques, que ja era batlle de la vall el 1318 (48), i després, des del gener de 1320, per Joan Enric (49). A més hi hagué, almenys el 1324, un procurador fiscal que també li prengué competències (50). Finalment, però, el 1328, regnant ja Alfons el Benigne, fou desenterrada l'anul.lació del càrrec de procurador fiscal de temps de Joan Rolf i el rei la confirmà; per tant, suprimit el càrrec, les seves competències, quedaren, com en aquell cas, atribuides al batlle general (51).

Les competències que Jaume II concedí expressament a Jaume Andreu, quan li confià el càrrec de batlle general, foren les d'establir en emfiteusi, fixar censos de les terres i aigües del Patrimoni, etc., competències que solien anar implicites en la concessió del càrrec, però que alguna vegada, com en aquest cas, s'especifiquen a part (52).

Com en el cas de Ferrer Descortell, també es conserven a l'Arxiu de la Corona d'Aragó algunes cartes originals de Jaume Andreu al monarca. La primera, del 1320, es refereix al perill d'un atac granadí que prenia perfils alarmants, puix que es deia que Múrcia i Lorca havien arribat a un acord amb els nassarites per a deixar passar llurs tropes, quan anessin a atacar terres oriolanes, sense declarar l'alerta i per a avisar-los, al contrari, si tropes catalanes travessaven el territori murcià per atacar el regne de Granada. Els rumors no eren pas sense fonament, com ho demostrà la carta que, un any després, l'adelantat de Múrcia adreçà a Jaume II (53). L'altra carta original de Jaume Andreu que hem trobat era una consulta al rei sobre el problema del càstig que havien de rebre els pastors aragonesos que, després de desobeir les prohibicions de passar el Segura amb llurs ramats, havien resultat capturats, alguns d'ells i una part de llurs ramats, pels genets granadins en el Camp de Cartagena. El batlle recomanava el càstig per a donar exemple i a més per reaons pràctiques, ja que les rendes d'Oriola, Alacant i Guardamar no bastaven per a pagar els salaris dels oficials ni per a mantenir els castells, i només podia confiar en els diners de les multes i penes judicials per a cobrir despeses (54).

\section{Joan Enric}

Jaume Andreu fou substituït per Joan Enric, que rebé el seu nomenament de batlle de la part del regne dellà Xixona el 14 de febrer de 1329 (55). 
Com ja ho hem dit abans, Joan Enric havia estat fins llavors batlle de la vall d'Elda i Novelda i precisament, en qualitat de tal, figura com a autor d'una de les cartes conservades a l'Arxiu de la Corona d'Aragó; una carta en la qual informava el rei sobre una incursió fronterera de castellans que havien robat bestiar (56)

\section{LA BATLLIA DE L'INFANT FERRAN}

La donació de la major part de les viles i dels llocs de la governació a l'infant Ferran, pel gener de 1330 (57), féu que el càrrec de batlle general d'aquella part del regne de València, com el de procurador, desaparegués per a passar a ésser el batlle particular de l'infant. Són ben poques, doncs, les notícies sobre l'administració d'aquelles terres que hem pogut recollir per a aquesta etapa. Un llibre de comptes de la batllia general dels llocs de l'infant Ferran, corresponent al 1355 amb algunes dades que arriben al 1356, ens informa que del 1355 al 1358 fou batlle general Joan Ximenis de Perencisa. Pel juny de 1358 fou substituitt per Aguerot Alvarez d'Espejo (58).

\section{LA BATLLIA GENERAL DEL REGNE DE VALĖNCIA DELLÀ XIXONA DES DE 1364}

\section{Joan d'Olit}

No tenim més notícies de l'administració d'aquell territori fins el 1364, un any en el qual Pere el Cerimoniós, després de l'assassinat del seu germà, l'infant Ferran, nomenà novament un batlle general del regne de València dellà Xixona, ja que aquelles terres es reincorporaven a la Corona, puix que l'infant no tenia descendència. El nomenament recaigué en Joan d'Olit, ciutadà de València, a qui fou assignat un salari de quatre animals diaris, més 20 lliures d'ajuda per al vestir (59). Després de poc, el rei l'afavoria encara amb la concessió de la batllia local d'Alacant (60). Però poca cosa degué poder fer, perquè ben aviat totes aquelles terres caigueren sota el control castellà a causa de les desgraciades vicissituds de la guerra amb Castella, dita dels dos Peres.

Pere el Cerimoniós recuperà aquelles terres meridionals el 1366 i, pel maig, Joan d'Olit començà a exercir el seu càrrec (61). Durant els mesos següents el rei anà precisant les competències del nou batlle: el 15 de juny el nomenà 
procurador fiscal; un càrrec que, com hem vist, havien acumulat alguns predecessors seus (62); també el 16 de juny li concedí poders per a establir en emfiteusi les terres i cases pertanyents al patrimoni reial i l'autoritzà a fer composicions amb els inculpats en qüestions civils o criminals derivades dels drets reials (63).

Després, pel setembre, el rei restringia involuntàriamente les competències de la batllia reinstaurada en confirmar una concessió vitalícia de la col.lectoria d'Elda, Novelda i Asp a Francesc Masquefa d'Oriola i un dels seus hereus, concessió que havia atorgat el 1364. Però l'endemà mateix d'aquesta confirmació el rei la revocava en adonar-se del perjudici causat a l'ofici de la batllia general, a la qual, a més de competències, sostreia unes rendes que servien per a pagar las retinences dels castells (64).

La tasca de Joan d'Olit no degué pas ésser fàcil. Hagué d'enfrontar-se amb un país destruït per la guerra, on la població havia sofert una disminució molt forta, especialment de sarraïns i jueus, que eren els qui portaven més benefici econòmic al Patrimoni reial. Calia intentar atreure població als nuclis urbans i calia reconstruir sèquies, cases i molins i replantar els arbres i els ceps talats pels exèrcits. Calia també reconstruir castells i muralles afectats pels setges $i$ tot això sense recursos: els camps havien restat improductius perquè la guerra no havia permès de sembrar-los i el rei no en podia cobrar les rendes, com tampoc no podia cobrar les rendes d'altres menes de conreus, arbres fruiters o vinyes si, com dèiem, havien estat talats i calia replantarlos. També es perdien els censos de les cases, molins, etc. destruïts, i no podia exigir la totalitat dels impostos personals als sarraiins si aquests darrers $s$ 'havien quedat pràcticament sense bestiar, sense collites i molts a la misèria.

La situació continuava essent molt difícil encara el 1368, després d'haver passat més de dos anys des de l'acabament de les operacions de guerra en aquest sector. Pel desembre d'aquest any, Joan d'Olit anà a trobar el rei Pere el Cerimoniós a Cervera per fer-li saber que els castells estaven a punt d'ésser abandonats pels alcaids, perquè ell no els podia pagar les retinences, i proposà que les rendes reials de Xàtiva fossin aplicades a aquesta obligació (65). Uns quants mesos després, el rei havia trobat una solució transitòria per a aquest greu problema, després d'haver-lo estudiat amb el mestre racional. Segons aquest alt oficial, veritable ministre d'Hisenda, el rei rebia en aquells moments 3.200 sous de renda a les terres dellà Xixona, mentre que els càrrecs que pesaven sobre les esmentades rendes ascendien a 26.000 sous o més. D'altra banda, el tresorer l'havia informat que no rebia rendes suficients en cap regne per a poder-les destinar a aquella obligació; així és que hi hagué 
d'aplicar 20.000 sous anuals dels que el tresorer de la reina lliurava cada any al monarca per al vestir i les altres necessitats de la seva cambra, ja que les rendes de la reina no estaven tan carregades com les seves pròpies (66). Una solució definitiva, almenys durant molts anys, per a aquest problema fou adoptada el 21 de juliol de 1376 . Consistí a transvasar 12.000 sous cada any de la batllia general del regne de València, més rica, a la de dellà Xixona, quantitat que havia de servir per a pagar les retinences dels castells (67).

Aquest transvasament de l'una batllia a l'altra suposà una supeditació, almenys en aspectes econòmics, de la batllia meridional a la gran batllia del regne de València. De fet, però, la batllia dellà Xixona ja li era en certa manera subordinada pel fet que Joan d'Olit era lloctinent del batlle general del regne i ensems batlle de la part meridional (68).

D'altres problemes derivats de la guerra, a més dels de la reconstrucció que ja hem citat, foren confiats també per a llur resolució a Joan d'Olit. Així, per exemple, el 25 de juliol de 1367 el rei Pere li encomanà la resolució dels plets contra els sarraïns que havien estat lliurats com a rehenes o que havien estat captivats per les seves tropes a Elda, Novelda i Asp, i que fugiren i tornaren a llurs llocs d'origen, ocupats pel rei de Castella. Era un problema una mica complicat perquè hi havia persones que havien comprat aquests captius i que ara els reclamaven, mentre que, d'una altra banda, el rei havia posat sota el seu guiatge els sarraïns d'Elda perquè poguessin tornar en aquest lloc a viure-hi (69).

Pere el Cerimoniós reconegué la importància del serveis prestats per Joan d'Olit en circumstàncies tan difícils i ens consta que els hi recompensà: per l'agost de 1367, en una ocasió en què Joan d'Olit havia acudit a la cort, suposem que per afers del seu càrrec, li concedí un donatiu de 2.000 sous, que equivalia, més o menys, a dos terços del seu salari anual (70).

Més tard, el monarca confirmà la permuta que Joan d'Olit havia fet amb el notari alacantí, Miquel Sánchez de Linyan; aquest darrer li havia cedit l'escrivania de la duana del port d'Alacant i ell li havia cedit la batllia, que, com ja ho hem dit, li havia concedit el rei el 1364. El càrrec de batlle general no li permetia de residir a Alacant i li resultava molt carregós haver d'acudir-hi per a presidir el consistori o consell municipal; al contrari, l'escrivania de la duana, podia regir-la, per concessió reial, per mitjà d'un substitut (71).

\section{Domingo Borràs}

Joan d'Olit mori el 1376 i el substituí Domingo Borràs, que fou nomenat el 18 de juliol de 1376 (72). Com d'altres predecessors seus, Domingo Borràs 
era un escrivà del rei (73); el 1373, juntament amb Guillem Mir, havia recaptat el monedatge o morabetí a les terres della Xixona i potser fou aquesta circumstància la que féu que el rei pensés en ell per al càrrec de batlle general (74).

Pel que fa al salari, fou igual que el dels seus predecessors immediats: quitació de quatre bèsties, que corresponia a 3.880 sous, més 400 sous per al vestir.

Pel que fa a competències, degueren ésser també semblants a les dels seus predecessors; no tingué, però, el càrrec de procurador fiscal, que molts havien acumulat, ja que sabem que aquest càrrec fou exercit pel notari d'Oriola, Joan Castell (75). El 1380 el rei amplià les atribucions de Domingo Borràs autoritzant-lo a fer composicions amb les persones acusades de crims que no fossin heretgia, lesa majestat i fabricació de moneda falsa (76).

D'altra banda, sabem que havia estat dues vegades col.lector del morabetí o monedatge, l'una el 1373, abans d'ésser batlle general, i l'altra el 1379, quan ja ho era. La primera vegada compartí el càrrec, com ja ho hem dit, amb Guillem Mir, i la segona amb Francesc Marrades. Per ambdós treballs Pere el Cerimoniós li assignà, el 1382, un salari de 4.000 sous barcelonins (77). El 1381 el rei li confià a ell, a Pere Marrades i a Arnau Porta els afers relacionats amb un censal que havia obligat als banquers, Pere Pasqual i Arnau Esquerit, per a respondre d'un crèdit de 9.000 lliures, pel qual havia hagut de pagar un interés o mogubell de 6 sous per lliura anuals (el 30\%) (78).

El rei recompensà els seus serveis de diferent manera: d'una banda concedint-li la batllia d'Alacant, que ja havia tingut el seu predecessor, Joan d'Olit (79), i d'una altra amb algun donatiu extraordinari, com per exemple el de 5.000 sous barcelonins, que li concedí el 1380 i que ell cobrà de les rendes de la batllia l'any següent, 1381 (80).

Domingo Borràs renuncià al seu càrrec per l'abril de 1384, perquè ja era molt vell i no podia tenir-ne cura. El rei encomanà llavors la batllia general a Pere Mir, de la casa reial (81).

\section{Pere Mir}

Sembla que el nomenament de Pere Mir ja havia estat signat el 15 de març de 1384. El càrrec li fou concedit a beneplàcit amb el mateix salari que havien tingut els seus predecessors i l'exercí des del primer de maig de 1384 fins al 2 de març de 1387, en què prengué possessió el seu successor, Joan de Roncesvalls. S'ha conservat el seu llibre de comptes que comprèn aquests 
anys i també hem conservat l'albarà de quitament que li lliurà el mestre racional després de rebre els comptes, el 1388. Segons aquest albarà, les rebudes del primer any de la seva administració havien sumat 22.488 sous i 8 diners, 24.833 en el segon i 25.133 sous i 8 diners en el tercer: en total 72.455 sous, 4 diners. Pel que fa a les despeses, havien pujat a 20.062 sous el primer any, 26.439 sous, 11 diners el segon i 26.090 sous, 8 diners el tercer, de manera que les despeses totals havien pujat a 72.592 sous, 7 diners $i$, per tant, havien superat les entrades en 137 sous, 3 diners, que el mestre racional reconegué que la cort li quedava a deure (82).

\section{Joan de Roncesvalls}

Potser a causa de la virada política que suposà l'accessió al tron de Joan I, el qual substituí molts dels alts oficials nomenats pel seu pare, el batlle general dellà Xixona fou rellevat del seu càrrec, tal com també li havia esdevingut al governador general, i fou substituit per Joan de Roncesvalls, un donzell que era cambrer de Joan I. El nomenament fou signat el 15 de gener de 1387 però, com ja ho hem dit, no prengué possessió fins el 2 de març d'aquell any (83). Un any després, el càrrec li era concedit amb caràcter vitalici (84) i, al cap de dos mesos, Joan de Roncesvalls era honorat encara amb la concessió del grau de cavaller (85).

Quan Joan I morí, Joan de Roncesvalls conservà el seu càrrec, malgrat les nombroses substitucions d'oficials reials que es produïren a causa del procés obert contra molts dels oficials i consellers del monarca difunt. Consta que el rei Martí manà al governador dellà Xixona $i$ als altres batlles $i$ justícies que no el molestessin en l'exercici del seu càrrec, ja que el tenia amb caràcter vitalici (86). Posteriorment, sembla que tingué alguna dificultat amb la cort, que s'aclarí amb una seva visita al monarca (87).

L'època en què Joan de Roncesvalls estigué al front de la batllia general dellà Xixona es caracteritzà per les dificultats amb què topà per a mantenir la independència i el rang d'aquella batllia, que corria el perill de convertir-se en un apèndix o una lloctinència de la batllia general del regne de València.

Ja hem dit que la guerra amb Castella havia arrasat aquelles terres de tal manera que passaren molts anys abans no començaren a refer-se'n i això incidí, com és molt natural, en les finances reials, que veieren com les entrades es reduïen a causa de les moratóries i condonacions d'impostos que calgué concedir a la població empobrida i a causa, també, de la pèrdua de béns (bestiar, arbres, cases o molins establerts a cens, etc.) i la disminució de població gravada pels impostos. 
D'altra banda, el rei s'havia desprès de totes les possesions que produien rendes més considerables: Elx i Crevillent foren donades a l'infant Martí, després de la mort de l'infant Ferran, $i$ Elda ${ }_{1}$ Novelda i Asp foren donades primer a Hug de Calviley i després a la reina Sibil.la, possessions que més tard passaren a la reina Violant.

Sota l'administració de la batllia general quedaren, doncs, només Oriola i Alacant amb llurs termes, però ambdues viles, gairebé desproveïdes de llur població sarrainna, proporcionaven poques rendes i grans despeses a causa de llurs castells, que eren les claus de la frontera i necessitaven sovint obres de reparació molt costoses i el manteniment d'una petita guarnició.

Ja hem dit que els ingressos del Patrimoni a la batllia dellà Xixona no cobrien les despeses i que, el 1376, Pere el Cerimoniós hagué d'ordenar la transferència anual de 12.000 sous de les arques de la batllia general del regne de València a les de la batllia dellà Xixona, a fi que es poguessin pagar las retinences dels castells, especialment dels d'Oriola i Alacant.

La dependència econòmica comporta sempre dependència politica $i$ administrativa; així que, insensiblement, el batlle general dellà Xixona anà perdent facultats reals de disposició, tant sobre els mateixos diners transvasats de la batllia general del regne de València com sobre la cura dels castells als quals anava destinada l'ajuda.

El 1384, mentre encara era batlle general dellà Xixona Domingo Borràs, el rei Pere li manà que retornés a la batllia general de València el que sobrés dels 12.000 sous traspassats per aquesta un cop hagués pagat les retinences i les obres dels castells d'Oriola i d'Alacant, ja que era just que la resta servís per a pagar els càrrecs d'aquella batllia (88).

Potser per tal de vigilar de prop la devolució d'aquestes restes i en general l'administració dels diners que sortien de la mateixa batllia, el batlle general del regne de València intervingué directament, més tard, en la decisió i l'execució de les obres que calia fer en els castells esmentats. El 1389, per exemple, Joan I recomanava a Ramon de Soler, que era llavors batlle general del regne de València, que inspeccionés el castell d'Oriola, ell o un seu lloctinent, i que hi fes fer les obres de reparació que fossin necessàries, ja que hom li havia dit que el castell, situat a la frontera amb Castella i un dels més insignes, amenaçava ruïna (89).

Més endavant, el 1394, Joan I disposava que, per tal d'evitar despeses inútils, els 6.000 sous de retinença que calia pagar a l'alcaid del castell d'Oriola els pagués directament el batlle del regne de València a l'alcaid d'Oriola (o 
al seu substitut), sense que haguessin de passar abans per les mans del batlle dellà Xixona com fins llavors (90). El mateix any, el rei destinà 5.000 sous a les obres de reparació de murs, torres, etc. del castell d'Oriola per a esmerçarlos en tres anys i uns altres 2.500 al d'Alacant, que també es trobava molt arruïnat; i ho comunicà no pas al batlle dellà Xixona, a qui hauria pertocat, sinó al batlle del regne de València, Ramon de Soler, a qui advertí que aquesta quantitat era de més a més del que ell hi destinava (91).

Ja en temps del rei Martí l'Humà, foren atribucions generals les que li foren discutides al batlle dellà Xixona. Així, per exemple, pel juny de 1397, Martí l'Humà li manà que no concedís llicències d'armar en cors, cosa que, deia, corresponia al batlle general del regne de València per costum antic. El rei reconeixia que el batlle no havia pas obrat sense base legal, puix que es referia a les llicències que havia concedit en vigor d'algunes cartes reials, però creia que,per a evitar danys, era millor que hi hagués un sol responsable de la concessió d'aquestes llicències en tot el regne (92). Sembla que aquesta actitud reial es devia als atacs de Joan Alvarez d'Espejo, veí d'Oriola, contra vaixells castellans i genovesos sota la protecció castellana a les mars de Castella, un fet que havia provocat represàlies contra mercaders catalans i habia posat en perill la pau amb Castella, segons ho assegurava el rei. Joan Alvarez d'Espejo habia armat una galicta a la governació dellà Xixona i havia donat fermances al batlle general d'aquesta regió comprometent-se a no atacar amics. El batlle el sentencià a mort per aquest fet, peró no fou trobat $i$ sembla que també hi hagué dificultats per a confiscar els seus béns i els de les fermances per a poder indemnitzar les víctimes, ja que la família de Joan Alvarez d'Espejo era molt poderosa a Oriola (93).

Fets com aquest s'esdevenien també en altres llocs i, bé que potser a l'extrem meridional de les terres catalanes les autoritats eren més benèvoles a causa de la situació fronterera, sembla que darrera d'aquests intents de retallar les competències del batlle dellà Xixona hi havia, en realitat, el desig del batlle general del regne d'assegurar la seva competència exclusiva sobre diverses qüestions.

No era cert que les llicènciés d'armar en cors haguessin correspost al batlle general del regne de València per costum antic. Alguns dels documents que hem vist demostren, ben al contrari, que el batlle reial dellà Xixona s'ocupava d'aquesta qüestió. El 16 de desembre de 1320, per exemple, Jaume Il comunicava al batlle general a la part del regne de Valéncia dellà Xixona que havia remès a Pere Ballester, de Guardamar, la fiança que havia fet a Garcia Salfamàs quan havia armat en cors a Guardamar. La fiança era exigi- 
ble perquè Garcia Salfamàs havia robat alguns cristians que calia indemnitzar (94). Si el batlle s'havia d'ocupar en principi d'exigir la fiança, sembla que era perquè el fiador era responsable davant seu. El 23 de desembre de 1321, d'altra banda, el mateix rei Jaume II cridà l'atenció al batlle general dellà Xixona, Jaume Andreu, perquè demanava als corsaris que armaven a la vila una part del lucre obtingut més gros del que havia estat fixat en els privilegis atorgats pels reis de Castella a Alacant i que havien estat confirmats per Jaume II (95).

Era cert, en canvi, que alguns tractats internacionals, com ara els de Gènova de 1386 i 1390, havien restringit als ports de Barcelona, València, Mallorca, Menorca, Eivissa, Caller i l'Alguer la possibilitt d'armar en cors, per tal d'assegurar un control més fort dels corsaris (96), i que això suposava, de fet, una limitació de les facultats del batlle general dellà Xixona.

Però aquesta dels armaments corsaris no era l'única prerrogativa reivindicada pel batlle general de València, que en aquests anys es preocupà d'assegurar la seva competència exclusiva sobre aquesta i d'altres qüestions i també la seva preeminència sobre el batlle dellà Xixona. Pel maig de 1399 el batlle general del regne, que era llavors un conseller del rei, Nicolau Pujades, s'havia queixat perquè els governadors $i$ els altres oficials reials, tant deçà com dellà Xixona, no en tenien prou amb els límits de llurs jurisdiccions respectives i envaien les seves competències, establertes per provisions reials. El rei Martí encomanà al seu conseller, Ramon Tolzà, cavaller i doctor en lleis de València, que resolgués les contencions jurisdiccionals que es produïssin entre el batlle general i els altres oficials, tal com ja ho havia fet precedentment el rei Pere (97).

Per juliol, el batlle general del regne aconseguia una provisió reial molt important, que significava la seva victòria sobre els dos governadors del regne, que en virtud de delegaciones especials del rei intervenien en la resolució de qüestions diverses, sostraient-les de la jurisdicció ordinària.

En aquest provisió el rei revocava totes les concessions a oficials reials o a comissaris, atorgades pel rei Joan l i per ell mateix, que signifiquessin una minva de les atribucions del batlle general del regne de València i prohibia que cap governador, justícia, batlle o altre oficial del regne de València, tant deçà com dellà Xixona, ni cap comissari pogués concedir llicències per a armar vaixells en cors contra enemics ni licències per a treure coses prohibides del regne per mar i per terra, ni pogués atorgar llicència als moros per a emigrar a terres sarraïnes ni per a demanar almoina dins dels seus regnes $i$, consegüentment, ningú fora del batlle general no podria decretar prohibicions 
sobre aquestes matèries (prohibicions d'armar en cors o de treure determinats productes, per exemple) ni jutjar-ne els infractors (98). Totes aquestes facultats eren competència també, fins llavors, del batlle general dellà Xixona (99) i algunes, com la de concedir llicències d'emigració o per a demanar almoina als sarrains, així com també el càstig dels infractors, havien estat exercides pel governador general del regne de València per delegació expressa dels monarques, especialment del rei Pere el Cerimoniós, que alguna vegada, però, escoltant les protestes del batlle general, havia confirmat que eren competència d'aquest darrer (100).

No sabem si Joan de Roncesvalles recorregué contra aquesta decisió reial, que limitava les seves atribucions en matèries tan importants com la d'autoritzar l'extracció de mercaderies prohibides per mar o per terra cap a Castella o bé si acceptà la decisió reial. Com que no conservem llibres de comptes de la batllia general corresponents a aquests anys no podem comprovar aquest punt, que seria fàcilment verificable perquè, en els que tenim d'anys anteriors, hi consten sempre els ingressos per les llicències d'extracció de mercaderies prohibides.

De tota manera, sembla que la limitació de funcions fou efectiva, perquè a la darreria de desembre de 1403, alguns anys després d'aquella provisió, el rey Martí comunicà a Olf de Pròixida, governador llavors d'Oriola, i al mateix Joan de Roncesvalls que el batlle general de València, de voluntat seva, havia nomenat guardià de les fronteres i ports per a vigilar les mercaderies prohibides que es treien sense llicència del regne de València un tal Domingo de Borja, ciutadà de Xàtiva, que tindria jurisdicció des del Xúquer fins al regne de Múrcia. La preeminència del batlle general del regne semblava, doncs, clara (101).

Contràriament, malgrat els antecedents de la intervenció del batlle general del regne de València en la inspecció, decisió i execució d'obres del castell d'Oriola, ens consta que Joan de Roncesvalls s'encarregà per ordre del rei de pagar 500 sous anuals per a la reparació del castell d'Alacant (102).

El rei Martí defensà també łes atribucions judicials del batlle dellà Xixona $i$, el 1410, prohibí que en els afers judicials relatius a la batllia hi intervinguessin comissaris reials; només el batlle o el seu lloctinent podien intervenir-hi. A més, prohibí que hom pogués impugnar les demandes que el mateix batlle general dellà Xixona fes per causa de rendes i drets patrimonials (103).

Joan de Roncesvalls morí el 1411 durant l'Interregne, un any després de la mort del rei Martí. Segons Bellot, fou substituït per Bartomeu Togores, 
nomenat pel governador dellà Xixona, de qui era lloctinent, malgrat les protestes del lloctinent del difunt, que era Bartomeu Monsi de Castanyeda, a qui pertocava la substitució. Sembla que el consell d'Oriola protestà també per aquest nomenament, ja que el càrrec de batlle era incompatible amb el de lloctinent del governador (104).

\section{D'ALTRES CÀRRECS}

Depenien de la batllia general els batlles de les viles reials, Alacant, Oriola i Guardamar, però no ens n'ocuparem amb detall perquè potser és més adequat de fer-ho dins del marc de la història local de cadascuna d'aquestes poblacions.

Hi havia, encara, molts més càrrecs, des dels més importants, com el de lloctinent, fins als d'escrivans, col.lectors d'impostos o saigs.

\section{Lloctinent}

Sabem que el batlle general tenia sovint un lloctinent, però coneixem pocs noms d'aquests lloctinents. Només els de Bartomeu Romeu, que ho era el 1317 (105), Joan Castell, veí d'Oriola, que ho era entre 1379 i 1381 (106), Miquel d'Alcarràs, que ho era el 1385 (107), i Bartomeu Monsi de Castanyeda (108). No sembla que tinguessin un salari fix pequè tampoc no devien tenir feina seguida sinó ocasional, quan el batlle s'absentava. En alguns casos ja ocupaven d'altres càrrecs remunerats; per exemple, Joan Castell era procurador i advocat fiscal. Pel que fa a Bartomeu Romeu, la batllia li pagava cada any 150 sous perquè mantingués en servei del rei un rossí alforrat (109).

\section{Procurador fiscal i advocat assessor}

El de procurador fiscal era, en canvi, un càrrec remunerat, però no pas sempre independent del batlle. Ja hem dit que el portantveus de procurador, Arnau de Torrelles, havia recomanat al rei Jaume II, el 1316, que creés aquest càrrec a la batllia general dellà Xixona, a fi que s'ocupés de la defensa dels drets fiscals i del càstig dels oficials reials que incomplissin llurs obligacions. El càrrec fou concedit efectivament a Arnau Vermell d'Oriola, però després fou revocat a petició d'Oriola, que deia que no era necessari, i les seves competències foren adjudicades al batlle general (110).

La necessitat de la presència d'un jurista entre els oficials de la batllia s'havia fet tan evident, però, que al cap de dos anys, el 1318, el batlle general 
dellá Xixona, Jaume Andreu, obtingué el nomenament d'un advocat assesor, càrrec que recaigué en Bernat de Solsona, veí d'Alacant, amb un salari de 100 sous anuals (111). Segurament les competències devien ésser semblants a les que havia tingut el procurador fiscal pero, havent estat rebutjat aquest càrrec feia tan poc de temps, hom acudí a una altra titulació.

El càrrec de procurador fiscal ressuscità, però, desprès de poc i, el 1324, era ocupat per Guillem Fibla, que cobrava, com l'advocat assessor, 100 sous anuals (112). És possible que aquest càrrec continués vigent en els anys posteriors. El 1356, almenys, sota el senyoriu de l'infant Ferran, ens consta que hi havia un advocat fiscal de funcions similars a les del procurador, que era Bernat Julià, que cobrava un salari de 300 sous anuals (113).

Quan Pere el Cerimoniós recuperà les comarques dellà Xixona, acumulà tot primer el càrrec de procurador fiscal al de batlle general i Joan d'Olit, que ja era batlle, rebé aquest segon nomenament el 15 de juny de 1366, però no el degué exercir més enllà de dos mesos, perquè el mateix any 1366 ja ocupà aquest càrrec i el d'advocat fiscal el notari Joan Castell, el mateix que també fou després lloctinent del batlle; com que cobrà un terç del salari anual previst, suposem que degué començar a exercir-lo el mes de setembre de 1366 (114). Sembla que Joan Castell ocupà el seu càrec fins al 1387, almenys (115). És el darrer procurador fiscal del qual tenim notícia en l'època que estudiem.

\section{Escrivà de la batllia general}

Pel que fa a l'escrivà de la batllia general, era també un càrrec important; s'encarregava de rebre els comptes de l'administració de les rendes reials i de la col.lecta d'impostos dels oficials locals, dels col.lectors o dels arrendataris. Sembla que era auxiliat en la seva tasca per altres escrivans. El primer dels escrivans de la batllia dellà Xixona del qual coneixem el nom és Jaume Desclapers, veí d'Elx. S'ocupava d'questa tasca ja el 1316, amb un salari de 200 sous anuals (116), però no rebé el nomenament oficial fins el 1321. El 1325 Jaume II li concedí que tingués el càrrec amb caràcter vitalici (117), però uns anys després, el 1327, Jaume Desclapers es vengué l'escrivania a Berenguer Gavet, un veí de Xàtiva, que en pagà 400 sous. El rei Alfons el Benigne en confirmà la venda, puix que era d'una cosa patrimonial, el 1329, i concedí el càrrec a Berenguer Gavet, el comprador, també amb caràcter vitalici (118).

No sabem el nom de cap més escrivà fins el 1356, en què ens consta que el notari Pere Romeu regia l'escrivania de la batllia general amb un salari 
superior al que havien tingut els seus predecessors: 300 sous (119). El 1366, recuperat aquest territori perdut durant la guerra amb Castella, s'ocupà de l'escrivania durant un període breu, uns quatre mesos, el notari Jaume de Mora, que fou succeit aviat per un altre notari, Castelló de Bellver (120). EI 1366 l'escrivà ja havia canviat i era ara Joan Morató (121), mentre que del 1379 al 1385, almenys, ho fou Joan Diez, auxiliat pel notari Bernat Morrelles (122). Bé que Joan Díez apareix com a escrivà de la batllia en els comptes d'aquesta institució, des del 1379 , el seu nomenament oficial no es produí fins el 1382, després de la mort de Joan Morató. És possible que aquest darrer hagués estat substituit per vellesa o malaltia per Joan Díez i que aquest sigui el motiu pel qual el trobem com a escrivà des d'abans del seu nomenament. En la concessió a Joan Díez el monarca féu constar els valuosos serveis prestats per aquest notari durant la guerra amb Castella (123).

\section{Escrivans de ports i duanes}

Quant als escrivans, és difícil destriar els casos en què eren uns assalariats d'aquells altres en què l'escrivania era un monopoli arrendat o cedit, com d'altres, amb caràcter vitalici per a recompensar uns serveis, o bé a canvi d'un cens anual o bé de manera gratuita.

L'escrivania del port d'Alacant sembla pertànyer al grup de les que eren regides per un assalariat; fou cedida poc després de la conquesta d'Alacant a Jaume de Santa Creu, el qual havia de retenir el seu salari de les rendes que produia la duana (124). El seu successor, Pere de Lagunes, de casa del rei Jaume II, a qui fou concedit el càrrec amb caràcter vitalici quan mori Jaume de Santa Creu el 1314 (125), figura en els comptes de la batllia del 13161317 entre les persones que reberen un sou de la batllia general, en el seu cas 10 diners diaris, situació en la qual continuà segurament fins a la seva mort, esdevinguda el 1324 (126). El seu successor, Bartomeu Pedriça, que pertanyia a la cambra de la reina i que fou nomenat el 1325, sembla que tingué el càrrec en les mateixes condicions que ell (127).

Ens manquen les notícies d'aquesta escrivania fins el 1357, en què el rei la donà, juntament amb les de les cúries del justícia i del batlle, al notari alacantí, Miguel Sánchez de Linyán, a precs de l'infant Pere, comte de Ribagorça i Prades, i del seu conseller, Bernat de Cabrera, per tal de premiar els serveis de l'esmentat notari en l'adquisició del lloc, el 1356, durant la guerra amb Castella (128); aquesta concessió fou confirmada el 1366, després que Alacant hagué tornat a mans del rei Pere el Cerimoniós, a finals de l'esmentada guerra, perquè Miquel Sánchez de Linyán s'havia esforçat per fer tornar la 
vila a l'obediència de la Corona (129). Consta que aquest any 1366 cobrà com a salari del seu càrrec d'escrivà i també de guarda de la duana d'Alacant pels mesos que l'exercí, després de la recuperació del lloc, la quantitat de 112 sous, mentre que el 1368 cobrà el salari íntegre de 300 sous (130). El 1369, Miquel Sánchez de Linyán permutà la seva escrivania de la duana amb la batllia d'Alacant, que tenia Joan d'Olit (131).

Sabem, i aquestes son les darreres notícies que en tenim, que el càrrec de guarda del port d'Alacant fou ocupat entre 1377 i 1382 per Garcia de Verdú, que cobrà 300 sous anuals. Suposem que, com en temps de Miquel Sánchez de Linyán, els càrrecs de guarda i d'escrivà de la duana eren una sola cosa (132); el salari, almenys, era el mateix. El 1384 apareix com a guardià del port d'Alacant Pere Gallo, però els anys següents desapareix aquesta partida dels llibres de comptes (133).

Sembla que les altres escrivanies de duanes i ports funcionaren amb un règim semblant, algunes vegades associades, com en els darrers casos citats d'Alacant, amb el càrrec de guarda; així per exemple a Guardamar, on el guarda del port, presumiblement també escrivà, era de 1379 a 1386 un tal Bartomeu Ivanyes, que cobrà un salari de 100 sous anuals (134).

Malgrat que Elx estingué separat del Patrimoni reial durant molt de temps i que precisament la major part dels libres de comptes de la batllia que es conserven coincideixen amb aquestes èpoques i que, per tant, no hi ha comptes relatius a Elx, hem pogut reunir diverses notícies sobre l'escrivania de la duana dels sarrains d'Elx i la del port del Cap de l'Aljub, on sembla que l'escrivà tenia, com a les anteriors, el caràcter d'assalariat.

Quant a la duana dels sarraïns d'Elx, l'escrivà fou des del 1310 Bernat Saverdú. El 1321 el rei li nomenà un successor, quan encara vivia, en la persona de Gil d'Omest, mestre de l'infant Pere (135), però finalment fou un sarraí d'Elx, Jahie Alunbeni, que ja hi treballava, qui se'n féu càrrec el $1323 \mathrm{amb}$ un salari de 10 diners diaris, idèntic al que hem vist a la mateixa època a laduana d'Alacant, més una taxa que es cobrava pels albarans (136). Alunbeni era, des del 1318, col.lector dels impostos reials que es cobraven a la duana d'Elx, com ja ho veurem més endavant.

Molt més tard, abans del 1358, quan Elx pertanyia a l'infant Joan, sabem que l'escrivania fou encomanada al jueu d'Elx, Jucef Abentaurell, que, a més, ostentava el càrrec de torsimany o traductor d'Elx i de Crevillent i utestimoni» de la duana d'Elx, càrrec aquest darrer que semblava una mateixa cosa amb el d'escrivà (137). Per l'octubre d'aquest mateix any, després de l'assassinat 
de l'infant a mans de Pere el Cruel de Castella, Pere el Cerimoniós li confirmà aquests càrrecs i el 1360 ho féu la reina Elionor en nom de l'infant Martí, que havia esdevingut senyor d'Elx i de Crevillent (138).

Ben poc temps després, però, Jucef Abentaurell tingué algunes topades amb els oficials de l'infant a Elx, els quals tot primer l'acusaren de cobrar una comissió de tot el que venia l'aljama sarraïna d'Elx, cosa que no s'havia acostumat mai de fer, i després fou pres perquè, segons ho afirmava el procurador d'Elx, no li havia retut comptes de la seva administració. La reina encomanà a Berenguer Togores que investigués la qüestió de les comissions que cobrava i la informés sobre els càrrecs de testimoni i d'escrivà de la duana, així com del de torsimany, salaris que cobraven els qui els ocupaven, etc.; d'altra banda, quan fou pres, la reina volgué que hom li concedís el benefici de la llibertat sota fiança, com corresponia a fets civils, cosa que Domingo Llull, el procurador de la reina a Elx i a Crevillent, no volia concedir-li, i a més manà a l'alcaid de Crevillent, Berenguer Togores, que procurés que tingués defensor i temps per a preparar la defensa (139).

Un cop solucionades, sembla, aquestes qüestions, sorgí el problema de si el càrrec de testimoni de la duana podia ésser ocupat per un jueu i no havia d'ésser exercit necessàriament per un sarral. La reina demanà informació a Elx sobre aquesta qüestió (140), però suposem que fou solucionada favorablement per a Jucef Abentaurell, perquè pel novembre del mateix any 1361 la reina li fixà el salari per als seus càrrecs: 300 sous per al d'escrivà i 150 per al de torsimany (141).

Consta que el 1363 la reina envià a Elx Pere Martí per a repassar els comptes del procurador i batlle, Domingo Llull, i els de Jucef Abentaurell, així com dels altres moros $i$ jueus que haguessin exercit càrrecs administratius (142).

A finals de l'any 1367 fou destituit Jucef Abentaurell i fou nomenat per a ocupar ambdós càrrecs, tant el de testimoni-escrivà de la duana com el de traductor, un altre jueu d'Elx, Abrafim Abenbahe, amb un salari més baix, de 300 sous en total (143). Malgrat això, posà tant d'entusiasme en la seva feina que aconseguif fer augmentar el producte de les rendes d'Elx, que abans disminuïen contínuament; la reina Elionor el recompensà per aquest motiu, el 1372, amb la donació de 400 sous (144). Més endavant, gaudí també de la confiança de l'infant Martí, que el féu domèstic seu i li encomanà altres tasques: el 1375 la col.lecta dels impostos de les moreries d'Elx i de Crevillent i l'administració de les obres que calgués fer a la Calaforra, a l'alcàsser, als molins, banys, presons i duana d'Elx i al castell, a les anomenades «cases de senyorm, molins, banys, taverna i presó de Crevillent (145), el 1378 la re- 
captació del que els jueus i els moros li devien per dret de segell (146) i, el 1384, juntament amb Jaume Juny, batlle d'Elx, la col.lecta de 150 florins que l'aljama de jueus d'Elx li havia de pagar (147).

El 1385, no sabem si perquè les obres que li havien estat encomanades pujaven més que el pressupost de què disposava o bé perquè havia fet algun préstec a l'infant, la cúria d'aquest darrer li devia 5.200 sous que, a partir d'aquest any, Abrahim Abenbahe hauria de recuperar del que rendissin els «esdeveniments» de Crevillent, és a dir, les multes i totes altres penes pecuniàries derivades de l'administració de la justícia (148).

L'infant premià els seus serveis, el 1377, amb un donatiu de 60 florins d'or (149) i el posà sota el seu guiatge especial a ell i la seva família (150). El 1385, potser coincidint amb el final de la seva gestió com a col.lector d'impostos, li féu una remissió de les penes en les quals pogués haver incorregut (151).

Hem parlat de l'escrivania de la duana d'Elx i ens hem desviat una mica del tema per tal de recollir les notícies sobre altres tasques encomanades als qui la regiren. Ara ens ocuparem de l'escrivania del port del Cap de l'Aljub, el port d'Elx. Abans del 25 de febrer de 1317 la tenia un veí d'Elx, Bernat Despuig, que en fou privat en aquesta data a favor d'un altre veí de la vila, anomenat Convent Rayner; el rei Jaume II, però, es repensà després i decidí que, tan aviat com l'últim nomenat hagués tingut el càrrec un any, retornés a Bernat Despuig, que era un home expert. A la darreria de desembre, el càrrec li fou concedit, en efecte, de manera vitalícia, bé que amb l'obligació de mantenir un cavall o rossí alforrat per a la defensa del lloc (152). A la seva mort, el 1319, el succeí en el càrrec amb les mateixes condicions Pere Robert, de la casa del rei (153), que, però, malgrat que el tenia amb caràcter vitalici, hi renuncià el 1320 . Fou nomenat llavors Jaume de Santamaria amb les mateixes condicions (154).

És ben difícil saber si les altres escrivanies de les quals tenim notícies eren regides per assalariats o bé si eren cedides en emfiteusi o arrendament. Ens fa l'efecte que les que anaven lligades a la percepció de determinats impostos solien ésser regides per assalariats, mentre que les d'activitat més pròxima a la funció notarial solien ésser cedides en emfiteusi o arrendament. Creiem, doncs, que, a més de les escrivanies de les duanes ja ressenyades, l'escrivania de la partició de les aigües del rei o del senyor, a Elx, per exemple, devia ésser regida per assalariats. La partició de les aigües era una operació que es feia cada dia i de la qual calia portar un control molt acurat; sabem que en fou escrivà Jaume Vidal, des d'abans del 1307 al 1313 i que, després de la seva mort, ho fou Jaume de Vilanova (155). 
Igualment és probable que fos regida per un assalariat l'escrivania del mercat d'Elx; sabem que, d'abans del 25 de març de 1315, n'era titular un metge jueu d'Elx anomenat Abrahim, que fou substituït en aquesta data per Convent de Convent, un veí d'Elx, potser d'origen italià; el càrrec li durà poc perquè pel setembre fou concedit a un veí de Barcelona, Pere Falet, a qui un any després li fou atorgat amb caràcter vitalici (156). Potser oblidant aquest condicionament, el rei la concedi el 1322 a Esteve d'Ançano, veí d'Elx, també amb caràcter vitalici; no sabem si aquesta qüestió originà cap plet (157).

Les altres escrivanies que foren administrades més aviat com a monopolis, és a dir, cedides a cens o arrendades, tant aquelles de les quals tenim constància com les que suposem que es trobaven en aquest cas, les deixem per a tractar-ne en una altra ocasió.

\section{Col.lectors d'impostos}

També trobem entre els assalariats de la batllia general els col.lectors d'impostos; quan no eren arrendats, la batllia havia de tenir gent que es fes càrrec d'aquesta feina. Així, per exemple, el 1316, Bernat Saverdú era el col.lector del quirat i de l'almoixerifat d'Elx i cobrava també el lloguer de tendes, molins etc. que pertanyien al Ppatrimoni, mentre que Bernat Despuig cobrava els drets del Cap de l'Aljub (158). Recordem que ambdós personatges regentaven al mateix temps les escrivanies de la duana d'Elx i del port del Cap de l'Aljub, respectivament, de manera que llur feina era compensada amb el salari de l'escrivania.

A més, hi havia els col.lectors especialitzats en impostos sarrains. Per a aquesta tasca calia gent que comprengués l'algaravia, cosa que no era gens freqüent entre els cristians (159); per això els col.lectors eren, generalment, sarraïns o jueus.

Però no ens ocuparem ara en detall d'aquests col.lectors, perquè ens obligaria a comentar els impostos gestionats per la batllia; això ens allargaria massa i desbordaria els límits d'aquest article. Ja els comentarem en una altra ocasió (160). 


\section{NOTES}

1) Sobre aquest tema cf. J. M. del ESTAL, Corpus documental del reino de Murcia bajo la soberania de Aragón (1296-1304/5). Colección de documentos Medievales Alicantinos 1/1, Alacant, 1985, i M. T. FERRER I MALLOL, Moros i cristians, almogàvers i collerats a la frontera d'Oriola (s. XIV), tesi doctoral inèdita.

2) Cf. la bibliografia de la nota anterior, i, a més, J. TORRES FONTES, La delimitación del Sudeste Peninsular (Torrellas-Elche), 1304 y 1305, Múrcia, 1951.

3) Cf. la bibliografia de la nota $1 \mathrm{i}$, a més, J. M. del ESTAL, Conquista y anexión de las tierras de Alicante. Elche, Orihuela y Guardamar al reino de Valencia por Jaime II de Aragón (1296-1308), Alacant, 1982.

4) Sobre la batllia general del regne de València cal consultar les obres de L. PILES ROS, Estudio documental sobre el bayle general de Valencia, su autoridad y jurisdicción, València 1970, i M. TINTO SALA, Cartas del Baile General de Valencia, Joan Mercader, al rey Fernando de Antequera, València 1979.

5) ACA, C, reg. 340, ff. 94 r. (1296, maig, 31)

6) ACA, C, reg. 340, ff. 182v. - 183r. (1396, maig, 31).

7) ACA, C, reg. 194, ff. 262v. (1296, agost, 11) i 284v. - 285 r.

8) ACA, C, reg. 194, ff, $229 \mathrm{v}$, i 229 v. -230 r. (1296, agost, 9) i reg. 195, ff. 85 r.-v. i $87 \mathrm{v}$ -88r. (1297, octubre, 31).

9) ACA, C, reg. 195, ff. 123v. - 124r. (1298, febrer, 9).

10) El 13 de febrer de 1301, per exemple, el rei li manà que apuntés en aquest llibre el seu ballester Bernat Desbanch, que serviria a la frontera amb un cavall alforrat, i disposava també que li fossin donades heretats en el regne: ACA, C, reg. 199, ff. 46v. (1301, febrer, 13) i 46v. $-47 r$.

11) $A C A, C, c r$. Jaume II, núm. 3.460 (1301, abril, 3).

12) $A C A, C$, reg. 231, ff. 52r. - 53 r. (1303, maig, 1).

13) ACA, C, reg. 231, f. 54r. (1303, maig, 18).

14) ACA, C, reg. 196, ff. 170v, - 171r. (1298, març, 28).

15) ACA, C, reg. 200, f. 213v. (1303, abril, 18)

16) ACA, C, reg. 231, f. 53r. (1303, abril, 30).

17) Fou Berenguer Colrat: ACA, C, reg. 231, f. 54v. (1304, febrer, 1).

18) Fou Bernat Rovira: ACA, C, reg. 231, f. 55r.-v. (1304, octubre, 7).

19) ACA, C, reg. 231, f. 56r. (1304, desembre, 3). La concessió hagué d'ésser refeta més tard pequè Ferrer Descortell l'havia perduda: ACA, C, reg. 232, f. 366v. (1311, abril, 7).

20) ACA, C, cr. Jaume II, núm. 2.673

21) ACA, C, reg. 231, f. 60r. (1309, gener, 8).

22) ACA, C, reg. 232, f. 365r. (1309, març, 6). 
23) ACA, C, reg. 232, f. 366r. (1310, desembre, 3 i 6).

24) ACA, C, reg. 304, f. 140r. (1306, desembre, 14), f. 140v. (1306, desembre, 14) if. $141 \mathrm{r}$. (1312, abril, 13).

25) ACA, C, cr. Jaume II, núm. 4.185. El lloctinent de procurador, que era Pero López de Rufes, devia ésser a Alacant; hi era almenys el dia 9: cf. ACA, C, cr. Jaume II, núms. 3.545 i 3.546 (1308, juny, 9) i 3.553 (1308, juny, 12).

26) ACA, C, cr. Jaume II, núm. 3.523 (1308, juny, 3) i A. GIMÉNEZ SOLER, La Corona de Aragón y Granada, «Boletín de la Real Academia de Buenas Letras de Barcelona», IV (19071908), p. 364

27) ACA, C, cr. Jaume II, núm. 3.524 (1308, juny, 4).

28) ACA, C, cr. Jaume II, núm. 3.535 (1308, juny, 6).

29) ACA, $C$, reg. 164, f. 72r. (1317, novembre, 30); reg. 216, f. 127v. (1319, abril, 3) i reg. 171, f. 169r. (1321, febrer, 24).

30) ACA, C. reg. 203, f. 213 v. (1306, desembre, 14). El seu germà, Bernat, també havia estat agraciat amb un privilegi semblant el 9 d'octubre del mateix any: ibidem, $f$. $197 \mathrm{v}$.

31) ACA, C, reg. 232, ff. 341r. - 342v. (1316, juny, 22). Al càrrec de batlle general del regne, hi acumulà també el de procurador fiscal: ibídem, ff, 342v. - 343 r. (1316, juliol, 17).

32) ACA, C, reg. 171, f. 169r. (1321, febrer, 24)

33) ACA, C, reg. 340, f. 120v. (1296, juny, 4).

34) ACA, C, reg. 232, f. 368v. (1313, maig, 2) i ACA, C, reg. 232, f. 370v. (1314, febrer, 24).

35) ACA, C, reg. 232, f. 372v. (1314, agost, 1).

36) ACA, C, reg. 198, f. 268r.-v. (1301, febrer, 25).

37) ACA, RP, MR, reg. 1701, vers de la fulla de guarda.

38) ACA, C, reg. 232, f. 375r. (1316, maig, 21) i ibidem (1316, agost, 14).

39) $A C A, C$, reg. 232, f. 379r. (1317, desembre, 10)

40) ACA, C, reg. 244, ff. 205r. - 206r. (1317, desembre, 10).

41) $A C A, R P, M R$, reg. 1701, vers de la fulla de guarda i ff. 26 r. i 32 r.

42) $A C A, C$, reg. 215, f. 255r. (1318, març, 12).

43) $A C A, C$, reg. 172, f. 73v. (1321, octubre, 24).

44) ACA, C, reg. 215, f. 255r.-v. (1318, març, 10).

45) Havia substituît A. d'Antist: ACA, C, reg. 232, f. 337v. (1315, març, 6).

46) ACA, C, reg. 232, f. 379r.-v. (1317, desembre, 10) i ACA, C, reg. 504, f. 75r.-v. (1327, novembre, 25).

47) ACA, C, reg. 232, f. 379r. (1317, desembre, 10)

48) $A C A, C$, reg. 164, f. 151r.-v. (1318, gener, 1).

49) ACA, C, reg. 232, f. 385v. (1320, gener, 27).

50) ACA, RP, MR, reg. 1.702, f. 8 r.

51) ACA, C, reg. 504, f. 87r.-v. (1328, març, 24).

52) ACA, C, reg. 232, f. 380v. (1318, febrer, 7$)$.

53) ACA, C, cr. Jaume II, núm. 6.439 (1320, juny, 18) i núm. 6.785 (1321, juliol, 14), pub! per. A. GIMÉNEZ SOLER, La Corona de Aragón y Granada, «BRABLB», 4, p. 83.

54) ACA, C, cr. Alfons III, núm. 201 (1328, març, 29).

55) ACA, C, reg. 504, f. 102r. (1329, febrer, 14).

56) ACA, C, cr. Alfons III, núm. 109. (1328, febrer, 20).

57) ACA, C, reg. 480, ff. 13r. - 22r. (1329, desembre, 28), publ. per E. ABAD NAVARRO, El castillo de la Mola en la ciudad de Novelda. Trabajo histórico y arqueológico, Múrcia, 1928, doc. 16.

58) ACA, RP, MR, reg. 1.721, f. $1 \mathrm{r}$.

59) ACA, C, reg. 1.200 , f. 580v. (1364, juny, 18).

60) ACA, C, reg. 1.198, f. 253v. (1364, juliol, 5).

61) ACA, RP, MR, reg. 1.711, f. $27 \mathrm{r}$.

62) ACA, C, reg. 1.078, ff. 79v. - 80v. (1366, juny, 15).

63) ACA, C, reg. 971, ff. 161v. - 162v. (1366, juny, 16). 
64) ACA, C, reg. 971, f. 166r.-v. (1366, setembre, 15).

65) $\mathrm{ACA}, \mathrm{C}$, reg. 1.222 , f. 126r. (1368, desembre, 28).

66) ACA, C, reg. 1.081, f. 72v. - 73r. (1369, juliol, 12).

67) ACA, RP, MR, reg. $1.722, f .21$ :

68) ACA, C, reg. 1.090 , f. 8r.-v. (1373, novembre, 8).

69) ACA, C, reg. 914, f. 79v. (1367, juliol, 25) i reg. 737, f. 59r.-v. (1367, juliol, 25).

70) ACA, C, reg. 1.217, f. 215r. (1367, agost, 7).

71) ACA, C, reg. 972, ff. 66v. - 77r.-v. (1369, setembre, 14) Més tard, perd, Miquel Sánchez de Linyán es queixà al rei perque Joan d'Olit, com a batlle general, havia posat un lloctinent seu a Alacant, que retallava les competències d'aquell darrer i, per tant, resultava perjudicat en la permuta. El rei decidí que M. Sánchez de Linyán havia de tenir el càrrec de batlle exactament amb les mateixes condicions que el tenia Joan d'Olit: reg. 1.232, f. 20r.-v.

72) ACA, RP, MR, reg. 1.722, f. 3r.

74) Figurava com a tal el 19 d'abril de 1371: ACA, C, reg. 1.350, ff. 79v. - 80r. Cf. també RP, MR, reg. 1.723, f. 1 r.-v.

75) ACA, RP, MR, reg. 1.722, f. $127 \mathrm{~V}$

76) $A C A, C$, reg. 1.267, f. 133v. (1380, juny, 25)

77) ACA, C, reg. 1.280, f. 1r.-v. (1382, setembre, 10) D'aquesta quantitat en cobrà 3.377 sous, 1 diner el mateix any 1382; sembla que la resta ja l'havia cobrada abans: ACA, RP, MR, reg. 1.722 , f. $183 \mathrm{v}$.

78) ACA, C, reg. 1.000, f. 166r.-v. (1381, maig, 15).

79) ACA, RP, MR, reg. 1.722 , f. $127 \mathrm{v}$.

80) $\mathrm{ACA}$; C, reg. 1.267, f. 85r. (1380, abril, 25) i RP, MA, reg. 1.722, f. 164r.

81) ACA, RP, MR, reg. 1.722, f. $3 r$. i reg. $1.723, \mathrm{f}$. 1r. $-\mathrm{v}$.

82) ACA, RP, MR, reg. 1.723 i reg. 653, ff. 161r. - 162v. i 162 v. - 163r.

83) ACA, $C$, reg. $1.920, f .7 v$. (1387, gener, 15). El rei el recomanà al batlle general del regne de València i als altres oficials reials: ACA, $C$, reg. 1.920, ff. 72v. - 73r. (1387, juny, 26).

84) ACA, C, reg. 1.920 , f. 139v. (1388, desembre, 9).

85) ACA, C, reg. 1.920 , f. 192r. (1389, febrer, 3).

86) ACA, C, reg. 2.223, f. 10v. (1397, juliol, 6).

87) ACA, C, reg. 2.223, f. 45v. (1399, abril, 1).

88) ACA, C, reg. 1.105, f. 95r. (1384, març, 4).

89) ACA, C, reg. 1.920 , f. 149r. (1389, novembre, 2).

90) ACA, C, reg. 1.885, f. 174r. (1394, abril, 2).

91) ACA, C, reg. 1.983, f. 118v. - 119r. i 121 r.-v. (1394, juny, 1).

92) $A C A, C$, reg. 2.223, f. 12v. (1397, juny, 28)

93) Cf. per exemple sobre aquesta qüestió: ACA, C, reg. 2.111, ff. 62r.-v. (1397, juliol, 30) i 65 r. i reg. 2.119, ff. 28r.-v. (1398, octubre, 1), 97r.-v. i $97 \mathrm{v}$. - 98r. (1399, febrer, 17 i 18), reg. 2.121 , f. $105 \mathrm{r}$. $-\mathrm{v}$. (1399, febrer, 17$)$ i reg. 2.118 , f. 141v. (1399, abril, 22). L'afer encara durava el 1406: reg. 2.152, ff. 39r. - 40r. (1406, juny, 23).

94) ACA, C, reg. 219, f. 178v. (1320, desembre, 16).

95) ACA, C, reg. 172, f. 209r. (1321, desembre, 23). Cf. aquests privilegis relatius al cors concedits pels reis de Castella a Fueros y Privilegios de Alfonso X el Sabio al Reino de Murcia, ed. per J. TORRES FONTES, Múrcia, 1973 («Colección de documentos para la Historia del Reino de Murciam, III), doc. 14.

96) M. T. FERRER I MALLOL, La pace del 1390 tra la Corona d'Aragona e la Repubblica di Genova, "Miscellanea di Storia Ligure in memoria di Giorgio Falco», Genova 1966, p. 163.

97) ACA, C, reg. 2.223, ff. 44v. - 45r. (1399, maig, 20).

98) ACA, C, reg. 2.223, ff. 47v. - 48v. (1399, juliol, 12).

99) Sobre les llicències per a armar en cors cf. les notes $92,93,94$ i 95 . Sobre llicències d'emigració cf. ACA, C, reg. 1.080, ff. 181v. - 182r. (1369, febrer, 13) i reg. 1.090, f. 8r.-v. (1373, novembre, 8 ) 
100) ACA, C, reg. 1.056, f. 131r.-v. i f. 132v. (1340, juliol, 15) i M. T. FERRER i MALLOL, Els sarraïns de la Corona catalano-aragonesa en el segle XIV. Segregació i limitació de llibertats, en curs de publicació, docs. 79 i 132.

101) ACA, C, reg. 2.223, f. 87r.-v. (1403, desembre, 24).

102) ACA, C, reg. 2.239, f. 76r.-v. (1397, novembre, 3).

103) ACA, C, reg. 2.223, f. 166v. - 167r.-v. (1410, gener, 30).

104) P. BELLOT, Anales de Orihuela (sigios XIV-XVI), estudio, edición y notas de J. TORRES FONTES, Oriola, 1954-1956, I, p. 240

105) ACA, RP, MR, reg. 1.701 , f. 34r.

106) ACA, RP, MR, reg. 1.722 , ff. 130v. - 131r. i 162r.

107) Pere el Cerimoniós, assabentat que tenia un rossí molt bo, li demanà que el vengués a un preu convenient al batlle del regne de València, Pere Mir, que el compraria per a ell: ACA, C. reg. 1289, f. 158 r. $(1385$, abril, 20).

108) Cf. nota 104.

109) ACA, RP, MR, reg. 1.701 , f. $33 \mathrm{v}$.

110) Cf. abans, nota 38 .

111) ACA, C, reg. 232, f. 384r. i cr. Jaume II, núm. 6049 (1318, desembre, 17).

112) ACA, RP, MR, reg. 1.702 , f. 8 r.

113) ACA, RP, MR, reg. 1.721, f. $23 \mathrm{v}$.

114) ACA, RP, MR, reg. 1.711, f. 28v.

115) ACA, AP, MR, reg. 1.712, f. 30r.; reg. 1.722, ff. 127v. i 198 r. i reg. 1.723 , ff. 26v., $31 \mathrm{v} ., 40 \mathrm{v}$. i $46 \mathrm{v}$.

116) ACA, RP, MR, reg. 1.701 , ff. 10r, i 20 r.

117) ACA, C, reg. 233, f. 123v. (1321, gener, 24) 133 v. - 134r. (1325, abril, 27), Cf. també RP, MR, reg. $1.702, \mathrm{f}, 1 \mathrm{r}$.

118) ACA, C, reg. 504, f. 114r.-v. (1329, juny, 29).

119) ACA, RP, MR, reg. 1.721, f. 24r.

120) ACA, RP, MR, reg. 1.711 , ff. 28v. i 29 r.

121) ACA, RP, MR, reg. 1.712, f. 30r.

122) ACA, RP, MR, reg. 1.722, f. 128v., 140v. i reg. 1.723, ff. 29r.-v. i 35v.

123) ACA, C, reg. 1.279, ff. 167v. - 168r. (1382, octubre, 19).

124) ACA, C, reg. 340, f. 200r. (1296, juliol, 5).

125) ACA, C, reg. 232, f. 373r. (1314, setembre, 28).

126) ACA, RP, MR, reg. 1.701 , ff. 9r. i 19v. i reg. 1.702 , f. $7 \mathrm{v}$.

127) ACA, C, reg. 233, f. 133r. (1325, març, 9).

128) ACA, C, reg. 966, f. 99r.-v. (1357, març, 25).

129) ACA, C, reg. 910, ff. 122v. - 123r. (1366, setembre, 22).

130) ACA, RP, MR, reg. 1.711, ff. 28r., reg. 1.712, f. $29 \mathrm{v}$.

131) Cf. abans nota 70 .

132) ACA, RP, MR, reg. 1.722, ff. 132r., 145r., 153v., 183r. i reg. 1.723, ff. 27r. i 33v.

133) ACA, RP, MR, reg. 1.723, f. $28 \mathrm{v}$.

134) ACA, RP, MR, reg. 1.722, ff. 128r., 140r., 152v., 181r., 198r. i reg. 1.723, f. 27r., 33v., $42 \mathrm{v}$.

135) ACA, C, reg. 232, f. 365v. (1310, octubre, 19), 370r. (1314, gener, 16), f. 382r. (1318, març, 14), reg. 233, f. 124v. (1321, febrer, 15).

136) ACA, C, reg. 233, f. 128v. (1323, juliol, 1).

137) ACA, C, reg. 1.547, f. 20v. - 21r. (1358, octubre, 28).

138) ACA, C, reg. 1.569, f. 36r.-v. (1360, gener, 10).

139) ACA, C, reg. 1.569, f. 74 r. (1360, novembre, 12), publ. per J. BOSWELL, The Royal treasure, pp. 502-503 (aquest autor, pero, llegeix Abencavarell on nosaltres llegim Abentaurell). Cf. també al mateix registre, f. 80r. (1361, febrer, 20) i f. 80r.-v. (1361, febrer, 13).

140) ACA, C, reg. 1.569 , f. 93r. (1361, maig, 22). 
141) ACA, C, reg. 1.569, f. 121r. (1361, setembre, 24).

142) ACA, C, reg. 1.572, f. 26r.-v. (1363, novembre, 13).

143) ACA, C, reg. 1.572, f. 73r. (1367, desembre, 1).

144) ACA, C, reg. 1.578 , f. 128r. (1372, juliol, 10)

145) ACA, C, reg. 2.064, ff. 195r. - 196r. (1375, desembre, 10)

146) ACA, C, reg. 2.067, f. 127v. (1378, octubre, 24)

147) ACA, C, reg. 2.072, f. 110r. (1384, febrer, 8)

148) ACA, C, reg. 2.074, f. 63r. (1385, novembre, 20) i 63v. i 64r.

149) ACA, C, reg. 2.066, f. 177v. (1377, novembre, 5).

150) ACA, C, reg. 2.067, ff. 120v. - 121r. (1378, octubre, 22).

151) ACA, C, reg. 2.087, f. 144r.-v. (1385, novembre, 22)

152) ACA, C, reg. 232, f. 377r.-v. (1317, febrer, 25), f. 377v. (1317, març, 8) i ff. 378v. 379r. (1317, desembre, 11).

153) ACA, C, reg. 232, f. 384r. (1319, març, 7).

154) ACA, C, reg. 232, f. 386v. (1320, maig, 23).

155) ACA, C, reg. 231, f. 58r. (1307, febrer, 8) i reg. 232, ff. 369v. - 370r. (1313, juliol, 13).

156) ACA, C, reg. 232, f. 373v. (1315, març, 26), f. 374r. (1315, setembre, 23) i 376v. (1316, setembre, 25).

157) ACA, C, reg. 233, f. 127v. (1322, novembre, 4).

158) ACA, RP, MR, reg. 1.701, f. 1r.-v.

159) D. ROMANO, Judíos escribanos y trujamanes de árabe en la Corona de Aragón (reinados de Jaime I a Jaime (1), «Sefarad», XXXVIII (1978), p. 72.

160) Els impostos pagats pels sarrains, d'altra banda, els tractem a l'estudi Les aljames serraines de la governació d'Oriolax, en curs de publicació. 